\title{
Advancing From Kumbaya to Radical Collaboration: Redefining the Future Research Library
}

\author{
JAMES G. NEAL \\ Columbia University, New York, NY, USA
}

\begin{abstract}
ABSTACT. The research library community has developed an effective program of multi-institutional cooperation during the last 50 years. Conditions in technology, economics, and expanding service requirements demand a more radical approach to collaboration. The 2CUL initiative illustrates key opportunities to set aside the traditional models of research library operations and respond to new roles and responsibilities.
\end{abstract}

KEYWORDS 2CUL Project, radical collaboration, research libraries

Cooperation is part of the professional DNA of research libraries. From the conditions of knowledge scarcity over the centuries to the oppression of information and data overabundance in today's and tomorrow's library context, cooperation has been and will be a constant for service, success, and survival. The transformation of research library collections, services, and spaces continues to progress under the impact of rampant shifts in user behaviors and expectations, digital and network technologies, and deep fiscal challenges. But the definition and view of the research library as an independent and self-sustaining organization, collaborating and sharing resources on the margin, has persisted. The future health of the research library will be increasingly defined by new and energetic relationships and combinations, and the radicalization of working relationships among research libraries, between libraries and the communities they serve, and in new entrepreneurial partnerships.

The context for collaboration and innovation is rich and powerful. It combines rapidly evolving user requirements, a recognition of the need to

Address correspondence to James G. Neal, Columbia University Libraries, Butler Library, Room 517, New York, NY 10027, USA. E-mail: jneal@columbia.edu 
rethink redundant inefficient library operations, an increasing emphasis on unique resources, a focus on the need to achieve scale and network effects through aggregation, a mandate for systemic change, and the unprecedented economic pressures.

The potential and reality of collaboration cuts across the core responsibilities of academic libraries. Whether it is information selection (choosing), information acquisition (getting), information synthesis (organizing), information navigation (discovering), information dissemination (delivering), information interpretation (assisting), information understanding (educating), information use (applying), or information archiving (preserving), libraries must find new ways to work together in support of teaching and learning, and of research and scholarship.

But academic libraries are assuming new roles as traditional boundaries shift. Libraries are learning how to be better consumers, often negotiating and licensing content and software collectively. Libraries are aggressive intermediaries and aggregators of information, and, as publishers, are creating new innovative modes of scholarly communication. Libraries are partnering with faculty to expand their educational involvement beyond traditional bibliographic instruction, and to advance operational investigations as researchand-development organizations. Libraries are more entrepreneurial organizations, more concerned with innovation, business planning, competition and risk, leveraging assets through new partnerships to produce new financial resources. Libraries are also increasingly successful information policy advocates seeking through political relationships to influence national and global laws and legislation.

Radical collaboration encourages academic libraries to move in four new directions. The first is mass production, including back-room operations like acquisitions, cataloging, electronic resource management, and preservation, for example, that might be based in regional distribution centers rather than in every individual library. The second is centers of excellence, deep and shared polycentric strategies for specialized expertise or services. The third is new infrastructure, building the technologies and functionalities for areas like digital ingestion, processing, and archiving. The fourth is new initiatives, new programs and projects based on shared investment in experimentation. In all four cases, the measures of success must be quality, productivity, and innovation. Are we producing something new, saving resources, and achieving something better together than working alone? Radical collaboration requires bi- and trilateral collaborations, as multilateral approaches are often too shallow or are not successful. It involves a business and sustainability plan, a legal framework and governance structure, risk capital to get it started, and a shared competitive spirit.

There are remarkable and expanding venues for research libraries to collaborate: in library systems, in local and regional consortiums, as part of state and multistate initiatives, in national programs, in international 
partnerships, with the cultural community, with researchers, with publishers, with campus technology organizations, with information technology vendors, and with corporations and other private-sector partners.

Collection storage facilities are often examples of deep library collaboration. The Research Collections and Preservation Consortium (ReCAP) located on the Forrestral campus of Princeton University in New Jersey is a high-density, environmentally controlled shelving facility jointly owned and operated by Princeton, Columbia, and the New York Public Library (NYPL). An inventory and retrieval system enables easy, dependable and effective access to the 10 million items housed at ReCAP for library users. A shared governance structure provides policy and budget control, and the management has been outsourced to Princeton.

Similar cooperative models are being implemented for shared repositories of digitized content from academic libraries. Launched in 2008, and housed at the University of Michigan, the Hathi Trust includes the member libraries of the Committee on Institutional Cooperation/Big 10, the University of California system, the University of Virginia, and Columbia. Hathi serves as a trusted repository, guaranteeing the long-term preservation of digital books created through mass digitization projects, and providing expert curation and consistent access.

Academic libraries have developed new strategies to build shared print collections. As the availability of online scholarly resources grows, libraries face increasing pressure to optimize management of print collections. Consolidation and rationalization of holdings within and across institutions enables economies of scale that benefit individual institutions and the wider academic library community by reducing costs and eliminating redundancies in holdings. Two noteworthy cooperative Research Library Group (RLG) projects have proceeded. One focuses on discarding print back runs of JSTOR titles as compared with the usual practice of moving these volumes into storage. A second seeks to identify the policy and business requirements for managing library print collections as a pooled resource, including optimal overlap to ensure long-term preservation, interinstitutional agreements to raise trust and confidence, and the technical infrastructure. RLG concludes that a new business model is needed that will enable academic libraries to establish partnerships capable of sustaining the long-term future of print collections, distributing the costs and benefits of acquiring and preserving content in tangible formats, and allowing aggregate holdings to be right-sized in alignment with aggregate demand.

Our academic library collection development programs cry out for new and innovative collaborative strategies. But in the short term, the following assumptions, in my view, will persist and dominate our investment in content. Academic research libraries will continue to develop comprehensive collections in all formats as research libraries acquire what the world produces. Collections will seek to align with university academic priorities and 
funding realities. This means that we will need to take on new areas and let go some collections of historical importance. Coordination of collection development across the research library community will remain marginalized. Cooperative collection development is a remarkable disappointment. Academic research libraries will increasingly focus on distinctive and unique collections in service to regional and national scholarly audiences. Academic research libraries will build innovative bilateral and trilateral partnerships to expand content access and delivery. Will there be true and rigorous coinvestment in collection development, access, and preservation? Preservation and archiving of the cultural and scientific record will remain balkanized and episodic with no leadership coordination. National and global information policies will not facilitate the deep collection collaboration needed. Copyright in particular is a major barrier to rigorous cooperation and to the reality of collective collection sharing. Work of collection building will require a new approach to professional staffing and organization. Where will we recruit the combination of subject, service, technical, and professional skills we need? Collections will need to align more intimately with teaching and learning processes, integration of content into the classroom, and the online learning environment. User communities will create their own tools for discovering, disseminating, and managing content. Academic research libraries will assume expanded roles as new scholarly communication business models are implemented. New publishing roles, content enrichment, data curation and archiving, and discovery will be critical. More focus will be placed on data capture and analysis to support collection development decisions.

Building the digital library where quality equals content plus functionality creates new innovative partnerships for academic libraries. The digital library includes: published and licensed content, primary content drawn from special and unique resources, open Web content (including sites and documents of quality and relevance that we need to collect and preserve), and institutional content (including the records of our universities and the grey literature produced across the institution)—all increasingly multimedia and integrated with services and requiring software tools. Digital libraries are all about collaboration.

Preserving and archiving the analog and digital content creates new and essential opportunities for collaboration. How will content be held, accessed, secured, and cared for if academic libraries do not develop new capacities as repository, curator and steward? Preserving content that is converted to digital or born digital requires a new shared commitment to architecture, policies, tools, workflows, and standards. Content that is often ephemeral, dynamic, and vulnerable, for which integrity is important, is where an academy-wide commitment is essential.

We painfully lack national policy and strategic leadership for preservation. I challenge anyone to identify an organization in North America that is 
championing and planning our preservation program. This means that we lack progress on the policy front, to build for example more expansive exceptions for preservation into our national copyright laws. This means that we lack significant national investment in preservation activities-state and federal funding of sufficient magnitude and sustenance to make a difference. The impact of these gaps is extraordinary and plays out in very damaging ways. I am concerned about a remarkable absence of research in so many areas of preservation. We need to move to best practices and standards which are based on science. I am heartened by the work being done at Johns Hopkins University, supported by the Mellon Foundation to apply rigorous scientific inquiry into our conservation work. I am concerned about an erosion of coverage of preservation in our library and information science education programs, and specialist degree initiatives at risk. And finally, the lack of a well-developed and well-supported national preservation program means that we miss opportunities to build strong relations and collaborations with other countries and regions that are investing in both analog and digital preservation studies and actions.

The repository movement has influenced dramatically where researchers deposit their work, and the ensuing chaos which has infiltrated the scholarly communication systems demands new collaborative strategies with academic libraries playing a key leadership role. Repository fatigue is setting in: publisher repositories, disciplinary repositories, academic unit repositories, institutional repositories, individual repositories, government repositories, national repositories, preservation repositories, and so on. What is the authoritative, official and citable version? What version will survive? What versions will be modified? Will a system of master versions develop? Can new identity registries help out? How do we work together to integrate and rationalize repositories and the open-access agenda into the system of scholarly communication and collection development in our libraries?

Preparing for accountability and assessment creates important opportunities for new partnerships. This is a product of heightened institutional expectations and government mandates. By working together, we can generate effective and broadly embraced measures of user satisfaction, market penetration, success, impact, and cost effectiveness. System design for user-centered, participatory, experimental, interactive, and user supportive outcomes means a new collaboration with library customers. Do academic libraries influence successful graduates, efficient administrators, and productive faculty?

Advocating the information policy agenda creates important partnerships for academic libraries in the work of advocacy, education and action. All policy arenas bring libraries together and into powerful new relationships to advance the political agenda: intellectual freedom, privacy, civil liberties, education programs, research programs, Internet development, 
telecommunications, government information, appropriations, workforce policy, and copyright.

Library space provides new opportunities for collaboration. We need to ask new questions about the conception and application of academic library space. Why do individuals enter a space (motivation or objective)? How do individuals navigate a space (transportation or circulation)? How do individuals use a space (experience or productivity)? What is the balance among function, usability, and aesthetics? How do individuals relate to each other (private, Collaborative, or public)? What is the symbolic role of space (emotional/spiritual)? How does a space reflect or advance the larger organization (mission, success, or feel)? How does space enable flexibility and adaptability?

Collaboration through library space means adopting new guidelines for planning and design. Focus less on statistical and operational formulas. Focus more on diversity of need and personal adaptability/customization. Design for the agile rather than the static. Start with the user and not the collection. Start with the technology and not with the staff. Bring the classroom into the library. Bring the academy into the library. Conceive the library five years ahead. Think more about playground and less about sanctuary. Prepare for anxiety, disruption and chaos.

The core responsibilities of research libraries align well with the needs of big science. Therefore, partnerships at the project, campus, discipline, national and global levels will advance scientific discovery and progress, and support the interests of individual scientists and teams of researchers, universities and research centers, and funding agencies. There is a productive marriage of capabilities and needs between library and science researchers.

When scientists map the universe, investigate the gene, monitor the environment, they create massive data sets that require management and structure. They want new tools for curation/findability and for extraction and application. As part of multidisciplinary teams, they increasingly care about distribution and collaboration and they seek sophisticated capabilities like visualization and simulation. Perhaps most importantly they are focused on permanent storage and availability. Can the research library add value to these processes?

We must raise the level of awareness and understanding. We must advance new approaches and standards for long-term digital data curation. We must identify new roles for libraries in e-science infrastructure and services to the scholarly community. We must outline new information profession skills and new roles for librarians as part of research teams. We must develop new relationships with government agencies and scholarly societies. But academic libraries are not routinely participating in the scholarly forums and the scientific funding arenas for research cyberinfrastructure.

Effective faculty relationships are essential to the success of the academic library. Faculty as researchers are among the primary consumers of library 
collections and services. They also produce, as authors and editors, the scholarly literature that is acquired by the library. Their teaching activities and course requirements determine the nature and intensity of library use by students. Faculty members occupy positions of administrative and policy leadership, which influence the financial and political status of the library in the institution.

Faculty members bring diverse but important priorities, interests, and expectations to their work at the university. They seek personal advancement and recognition in their disciplines and, in some cases, academic administrative opportunities. They want to contribute to the literature and prestige of their fields and, therefore, often actively pursue external funding in the form of grants and endowments to support their work and that of their students. They strive to produce high quality instructional content and experiences, and to advance students into successful careers or prestigious graduate and professional programs. They are interested in working on innovative projects and collaborating with interesting and accomplished colleagues. They expect financial recognition of their efforts in the form of compensation and, as appropriate, profit from their publications, inventions, software, or expert consultation. And increasingly, they demand access to the best laboratory, technology, and library capabilities, as well as opportunities to experiment with computers and networks in their teaching and research. It is important that the library understand these motivations as relationships with faculty are reshaped.

There is a taxonomy of faculty and library relationships that is historically based and explains the two cultures which often coexist in the academy. Academic libraries in the United States in the past were largely administered by senior professors, and this continues to be the case in countries around the world. In this century, with the advancing professionalization of librarianship, the situation has changed rapidly in some settings, though the tension between the faculty and the librarian administrator often persists. Another important consideration is the diversity of the faculty in terms of discipline, tenure status, years at the institution and comfort with technology, for example.

A classification scheme of faculty and library relationships can be outlined. The servant relationship places the library in a position of responding to faculty demands without an opportunity to influence expectations and without mutual respect. The stranger relationship is characterized by faculty and library communities which do not work together but coexist independently in the academic setting. The parallel relationship describes a situation where faculty and library activities do not intersect, where library collections and services are underused and where faculty information needs are satisfied from other sources. The friend relationship positions the faculty and library as cooperative and mutually supportive more out of tradition than an intense dependence. The partner relationship is built on a mutual reliance 
and a shared commitment to improving the quality of both the library and the university. The customer relationship places the library and the faculty in a market relationship with a recognition of the consumer and broker nature of the interaction. The team or knowledge management relationship realizes a fuller integration of interests and activities and high level of personal investment in the collaboration. These descriptions of faculty and library relationships are not complete or mutually exclusive, but they do illustrate the evolution of the quality and impact of the interaction and can assist future development of this critical association.

The points of intersection between library and faculty include some traditional elements. Faculty use libraries, assist with the building of collections, involve librarians in educating their students, seek assistance with course readings, consult with librarians on their research, expect effective access to local and distant collections, advise and advocate for library development, participate in the policy and priority setting, and contribute personal collections and financial resources. Technology and networking are expanding the functional relationships as faculty increasingly turn to the library for assistance in other areas: Internet access, guidance to quality Web sites, assistance in the integration of technology into teaching, digital collections, sophisticated searching tools and information finding aids, new literature alerts based on research profiles, high-level equipment, and partners in research, for example. The challenge faced by the library is that these new faculty needs do not replace the traditional expectations, but create an incremental, sometimes exhausting and always schizophrenic demand for resources.

The 2CUL Project between Columbia University and Cornell University libraries is a transformative and enduring partnership between two major academic research libraries based on a broad integration of resources, collections, services, and expertise. Research libraries have successfully collaborated in the licensing of electronic resources, cooperative cataloging, interlibrary loan and document delivery, information policy advocacy, offsite shelving facilities, and digital archiving.

The goals of 2CUL are to: (a) achieve major integration of operations, services, collections and resources; (b) reduce cost of overall library activities to direct resources to new priority areas; (c) increase revenues through joint proposals for funding, new products and services, and business opportunities marketed to academic and research customers; (d) establish an independent service entity and governance structure that supports 2CUL; and (e) expand 2CUL beyond initial partners, and model collaboration for other groups of research libraries and for other divisions at the university.

The Columbia University and Cornell University libraries have come together as major research libraries in New York state, as private Ivy League institutions with similar academic characteristics, a record of collaboration, a record of innovation, budget challenges, and the will and interest to work together in new ways. We are initially focusing our work on technical 
services (i.e., acquisitions, cataloging, e-resource management), collection development and global resources, and technology infrastructure and digital preservation. A Mellon Foundation grant supports consultation (Ithaka) to provide project management, meeting facilitation, work plan development, research, independent perspective, data mining and analysis, governance, business planning and legal support, and meeting travel and teleconferencing equipment.

Another important new collaboration to consider is a program being developed among the libraries at NYPL, New York University (NYU), and Columbia University. The recently developed scope statement defines the purpose. The three comprehensive research libraries in New York City-NYPL, Columbia, and NYU-have a long history of cooperation and coordination. At the same time, that long history has also been, in some sense, stagnant and constrained. With major changes in the economy, in technology, in the patterns of library use, and in the expectations of library users, it is time to take an entirely fresh and more aggressive look at mutually beneficial programs of shared collecting and access. What greater access can each institution provide to the user populations of the other? If we can bring access to a new level, how can we then benefit from truly collaborative collecting? The goal of our meeting will be to identify how we can take advantage of our shared New York City location and our shared mission as comprehensive research libraries to move beyond our traditional programs of cooperation and coordination to a new level of deep collaboration that will actually change what we collect and how we do business with each other.

The initial planning meeting, involving management teams from the three libraries, considered as a first step the following questions:

1. What are the current areas of explicit and implicit collaboration among and between the three libraries?

2. What do we want to achieve through expanded and enhanced collaboration?

3. What do our users expect and require as they work across the three libraries?

4. What are the barriers to shared collections and access?

5. What are model efforts among other research libraries that we can explore and evaluate?

6. What are the three actions that we can take immediately to create expanded access?

7. What are the three actions that we want to pursue as priorities to test our ability to coordinate collection development?

8. How will we measure and evaluate progress?

9. How should we communicate with our user communities and administrations on our collective efforts? 
The discussions on collaborative collection development echoed the "conspectus" model promoted by the Research Libraries Group 30 years ago. The goal will be to define both the historical depth of collections in designated areas and the current and continuing investment. The discussion on access encouraged barrier-free access across the three libraries for the research users of the three institutions, these communities requiring clear definition and refinement, as well as expedited physical and electronic document delivery. The key barriers are physical, operational, policy, and financial. The discussions on electronic resources highlighted the need to negotiate for a collective collection that provides more content and more favorable terms than the three institutions could achieve separately.

Rosabeth Moss Kantor, a researcher at Harvard Business School has identified the characteristics of successful partnerships (Kanter, 1994).

- Individual excellence, in that the partners are strong and have something to contribute to the relationship.

- Importance, in that the relationship fits the strategic objectives of the partners and they want to make it work.

- Interdependence, in that the partners need each other and have complimentary assets and skills.

- Investment, in that the partners are willing to show tangible signs for a long-term commitment.

- Information sharing, in that communication is open and critical data is shared freely.

- Integration, in that the partners develop linkages and share in joint activities.

- Institutionalization, in that the relationship may adopt a formal status with clear responsibilities and decision processes.

- Integrity, in that partners behave towards each other in honorable ways that justify and enhance mutual trust.

This is the substance of a successful library and faculty collaboration.

Kantor also posits the key mechanisms for successful partnerships.

- Self analysis. Know yourself and your business and be able to evaluate a potential partner.

- Personal chemistry. The need for rapport among the players, a sense of commitment and respect.

- Compatibility. Shared values and aspirations. A compatible assessment of benefits and opportunities. Integration, including strategic and sustained contact focusing on broad goals and trends, tactical plans for specific projects and joint activities, operational through day-to-day work together, 
interpersonal through regular meetings and contacts, and cultural awareness and communication skills to bridge differences.

These characteristics and mechanisms will serve well the expanding collaborative venues being pursued by academic research libraries. The arenas and examples outlined in this article testify to the rich possibilities and the prospective benefits.

\section{REFERENCE}

Kanter, R. M. (1994, July/August). Collaborative advantage: The art of alliances. Harvard Business Review, pp. 96-109. 